\title{
THERMAL STUDIES ON POLYTHIOPHENE CONTAINING MESOGENIC SIDE CHAINS
}

\author{
S. Radhakrishnan ${ }^{1}$, N. Somanathan ${ }^{1 *}$, T. Narashimhaswamy ${ }^{1}$, M. Thelakkat ${ }^{2}$ and H. W. Schmidt ${ }^{2}$ \\ ${ }^{1}$ Polymer Laboratory, Central Leather Research Institute, Chennai 600 020, India \\ ${ }^{2}$ Macromolecular Chemistry I, University of Bayreuth, Bayreuth D 95447, Germany
}

\begin{abstract}
Series of thiophenes containing mesogenic side chains at the $3^{\text {rd }}$ position are synthesized. The thermal transitions and thermal stability of the synthesized monomers and polymers are studied. The polarizing microscopic studies of synthesized monomers showed nematic liquid crystalline phase and these mesophases further confirmed by differential scanning calorimetric study. The obtained melting and the isotropic temperatures decrease linearly with the increase of aliphatic chain length. The transition temperatures determined from DSC analysis, overlap well with the temperatures obtained from optical microscopy studies. Thermal stability of the compounds is analysed using thermogravimetric studies. Thermal stability of monomers and polymers has been determined by calculating IPDT values. Structural influence on thermal degradation patterns of monomers and polymers are also discussed.
\end{abstract}

Keywords: conjugated polymers, liquid crystalline materials, polythiophene, thermal stability, thermogravimetry

\section{Introduction}

Conjugated polymers are currently receiving much attention in opto-electronics [1]. Polymeric light emitting devices, polymeric lasers belong to the family of opto-electronic devices, which is expected to replace the conventional inorganic devices, and this technology could lead to a magneto-optical system for writing and erasing data from computer hard drives [2]. Among the polymeric emissive materials, functionalized polythiophenes are proven to be better candidates because of their synthetic versatility and solubility [3]. Introduction of liquid crystalline groups into the side chain of the conjugated polymer is expected to afford a higher electrical conductivity and a notable electrical anisotropy [4]. This is because the polymer main chain can be aligned by the virtue of spontaneous orientation of liquid crystalline side chains and further by macroscopic orientation of liquid crystalline domains by thermal annealing or under external force, such as shear stress and electric or magnetic field.

The selection of emissive materials for LEDs, even though primarily depend on fluorescence and electroluminescence (EL) characters, other properties like thermal stability are also important. This is due to the fact that in LEDs, the EL conversion efficiency is around $5 \%$ and the remaining electrical energy may dissipate in the form of heat. This thermal energy instantaneously raises the temperature of the emissive layer. Therefore, for PLED applications, it is mandatory that the polymer should have good thermal stabil-

Author for correspondence: nsomanathan@rediffmail.com

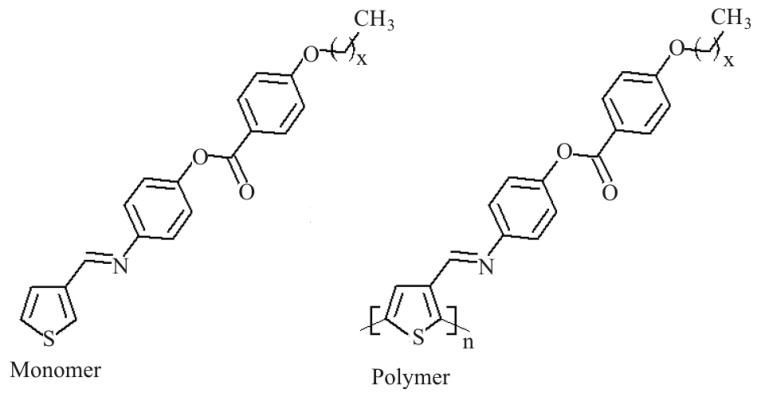

$\mathrm{N}$ series $(x=3,5,7$ and 9$)$

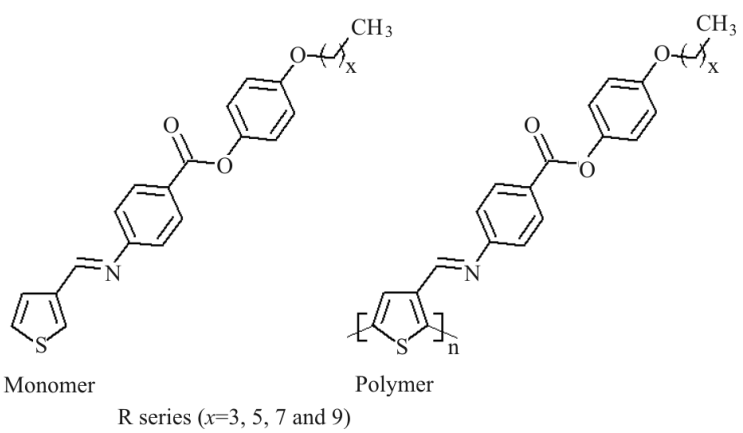

Fig. 1 Chemical structures of $\mathrm{N}$ and $\mathrm{R}$ series monomers and polymers

ity too [5-9]. In the present study, the thermal behavior of polythiophene model compounds containing phenyl groups linked with azomethine, ester, and alkoxy groups has been studied. The chemical structures of monomers and polymers of varying alkoxy chain length (4, 6, 8 and 10 carbons) are shown in Fig. 1. The $\mathrm{N}$ group structures have

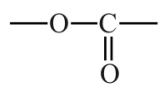


linkages between the phenyl groups, while the $\mathrm{R}$ group structures have

$$
-\underset{\mathrm{O}}{\mathrm{C}}-\mathrm{O}-
$$

linkages. These compounds show polarized electroluminescence in all base color ranges.

\section{Experimental}

General method of preparation for thiophenes with side chain bearing mesogens and spacer groups

Preparation of alkoxy benzoyloxy anilines

4-Hydroxy benzoic acid was reacted with alkyl bromide ( $\mathrm{RBr}, R=4,6,8$ and 10) in presence of potassium hydroxide $(\mathrm{KOH})$ in ethanol. The corresponding acid chloride was prepared using $\mathrm{SOCl}_{2}$. Then it is coupled with 4-hydroxy nitro benzene. The resulting nitro compound was reduced using tin(II) chloride [10].

Preparation of alkoxy phenoxy amino benzoates

4-Hydroxy phenol was reacted with alkyl bromide ( $\mathrm{RBr}, R=4,6,8$ and 10) in ethanolic $\mathrm{KOH}$ and it was coupled with 4-nitro benzoyl chlorides. The resulting compound was reduced using $\mathrm{SnCl}_{2}$.

\section{Preparation of Schiff's bases}

The amine recovered from above synthesis was dissolved in absolute ethanol and mixed with thiophene3 -carboxaldehyde. The monomer series obtained from the coupling of alkoxy benzoyloxy anilines are called $\mathrm{N}$ series and the products obtained from the coupling of alkoxy phenoxy amino benzoates are called $\mathrm{R}$ series.

\section{General method of preparation of polymers by electrochemical polymerization}

The electrochemical polymerizations of Schiff's bases were carried out in acetonitrile containing tetrabutylammonium hexafluoro-phosphate as the electrolyte. Current density for the polymerization reaction was $2 \mathrm{~mA} \mathrm{~cm}$ and the reaction was performed for $3 \mathrm{~h}$. Dedoping of the formed polymers was carried out for about $30 \mathrm{~min}$ by reversing the polarity. The time of reaction and dedoping were fixed on the basis of applied current. The above procedure was adopted for synthesizing all polymers. The structure of the all synthesized monomers is confirmed using the NMR and IR spectroscopic techniques.
The different phases obtained for monomers due to thermal transitions were observed using hot stage polarizing microscope. Thermal stability of the compounds was studied using thermogravimetric analysis. All TG experiments were carried out using Netzsch 409C thermogravimetric analyser in nitrogen atmosphere and using a program rate of $10^{\circ} \mathrm{C}$. Differential scanning calorimetric studies of monomers and polymers were carried out with the heating rate of $10^{\circ} \mathrm{C} \mathrm{min}^{-1}$ using Perkin Elmer DSC7.

\section{Results and discussion}

Molecular structures influence the degree of orientation in soluble poly 3-alkyl thiophenes differing both in side chain length and microstructure [11]. All thiophene monomers synthesized ( $\mathrm{N}$ and $\mathrm{R}$ monomers) are examined using polarizing microscope containing heating/-cooling stage with the heating rate of $10^{\circ} \mathrm{C}$. All the monomers showed nematic behavior by exhibiting thread like structures. Table 1 shows the melting and clearing temperatures of these synthesized monomers. In the case of $\mathrm{N}$ series monomers, the polarisability, phase stabilization and molecular interactions increase with the increase of alkoxy chain length in aliphatic segment. Overall the melting and the isotropic temperatures decrease linearly with the increase of aliphatic chain length. The molecular packing in solid state depends on the ratio of aliphatic to aromatic segments in the side chain. The melting temperature of $\mathrm{R}$ series monomers is high when compared to the corresponding $\mathrm{N}$ series monomers. In $\mathrm{R}$ series, even though the melting and isotropic temperature decreases, there is no characteristic variation after $\mathrm{C}_{6}$ in the aliphatic segment and the $\Delta T$ decreases with the increase of carbon chain length.

Mesophases can be well characterized by the thermodynamic properties [12]. Hence thermal transitions of all monomers were analysed using differential scanning calorimetry. The transition temperatures obtained from DSC analysis, overlap well with the temperatures obtained from optical microscopy studies. The corresponding transition energies obtained for different transitions are presented in Table 1. The first transition involves higher energy, which is due to the phase transition of crystalline (three dimensional) to nematic phase (uni-dimensional). The second transition-nematic to isotropic transition involves very low energy compared to that of first transition. In R series, the energy does not change up to R8 monomer and then the value decrease with the increase of aliphatic chain length. In R series monomers, energy for the $2^{\text {nd }}$ transition increases with increase of carbon chain length. The DSC analysis was undertaken for $\mathrm{N}$ and $\mathrm{R}$ series polymers (PN and PR series) and the obtained transi- 
Table 1 Melting and clearing temperatures of thiophene based liquid crystalline monomers and polymers

\begin{tabular}{|c|c|c|c|c|c|c|}
\hline \multirow{2}{*}{ Compound } & & \multicolumn{2}{|c|}{ Melting temperature } & \multicolumn{2}{|c|}{ Clearing temperature } & \multirow{2}{*}{$\begin{array}{c}\Delta T \\
\left(T_{\mathrm{m}}-T_{\mathrm{c}}\right) /{ }^{\circ} \mathrm{C}\end{array}$} \\
\hline & & $T_{\mathrm{m}} /{ }^{\circ} \mathrm{C}$ & $E / \mathrm{J} \mathrm{g}^{-1}$ & $T_{\mathrm{c}} /{ }^{\circ} \mathrm{C}$ & $E / \mathrm{J} \mathrm{g}^{-1}$ & \\
\hline \multirow{8}{*}{ Monomer } & N4 & 124 & 58 & 152 & 2.7 & 28 \\
\hline & N6 & 113 & 72 & 148 & 3.3 & 35 \\
\hline & N8 & 99 & 56 & 140 & 3.3 & 41 \\
\hline & N10 & 91 & 63 & 138 & 3.4 & 47 \\
\hline & $\mathrm{R} 4$ & 133 & 83 & 146 & 1.5 & 13 \\
\hline & R6 & 111 & 82 & 123 & 1.0 & 12 \\
\hline & $\mathrm{R} 8$ & 117 & 84 & 135 & 2.9 & 8 \\
\hline & $\mathrm{R} 10$ & 111 & 53 & 128 & 3.3 & 17 \\
\hline \multirow{8}{*}{ Polymer } & N4 & 102 & 1.4 & 139 & 0.04 & 37 \\
\hline & N6 & 102 & 1.5 & 138 & 0.07 & 36 \\
\hline & N8 & 102 & 1.4 & 139 & 0.02 & 37 \\
\hline & N10 & 102 & 3.2 & 140 & - & 38 \\
\hline & R4 & 102 & 1.6 & 139 & 0.03 & 37 \\
\hline & R6 & 102 & 3.0 & 129 & 0.05 & 27 \\
\hline & $\mathrm{R} 8$ & 102 & 3.4 & 134 & - & 32 \\
\hline & R10 & 102 & 2.6 & 139 & 0.03 & 37 \\
\hline
\end{tabular}

tion temperatures, and the energies involved in these transitions are presented in Table 1 . The results show that in polymers, irrespective of the linkage, the $1^{\text {st }}$ transition temperature is same. But the energy involved with this transition varies with carbon chain length. Like R10 monomer, R10 polymer also shows less energy for $1^{\text {st }}$ transition compared to R8.

Thermogravimetry is a powerful tool in assessing thermal stability of polymers [13-15]. Thermal stability of the compounds is monitored using thermogravimetry and the results are used to compare the thermal stability of different structures of thiophene monomers and polymers. The obtained curves for monomers of $\mathrm{N}$ and $\mathrm{R}$ series are presented in Fig. 2. The monomers of $\mathrm{N}$ series are stable up to $500 \mathrm{~K}$. Major loss starts around $550 \mathrm{~K}$ for N4 and N6 and both the compounds are stable up to $610 \mathrm{~K}$. In the case of monomers of $\mathrm{R}$ series, it is observed that all the monomers are stable up to $500 \mathrm{~K}$ and the major mass loss starts at $550^{\circ} \mathrm{C}$. R8 shows slightly better stability than R10.

The observed initial decomposition temperature (IDT) is presented in Table 2. The monomers of $\mathrm{N} 8$ and R8 show high value of initial decomposition temperature. In comparison to $\mathrm{R}$ series, $\mathrm{N}$ series monomers start decomposing at higher temperatures. The maximum decomposition temperature found to be high in the case of $\mathrm{N} 8$ and N10. In the R series, R8 is showing high value of $D_{\max }$. The results on IDT and $D_{\max }$ suggest that $\mathrm{N} 8$ and $\mathrm{N} 10$ monomers are thermally stable than other monomers and in the case of $\mathrm{R}$ series $\mathrm{R} 8$ showing higher stability than others.

Thermal stability of $\mathrm{R}$ and $\mathrm{N}$ series polymers (PN and PR series) is studied using thermogravimetric analysis and the curves are presented in Fig. 3. The observed initial decomposition temperature (IDT) is presented in Table 3. IDT increases with the
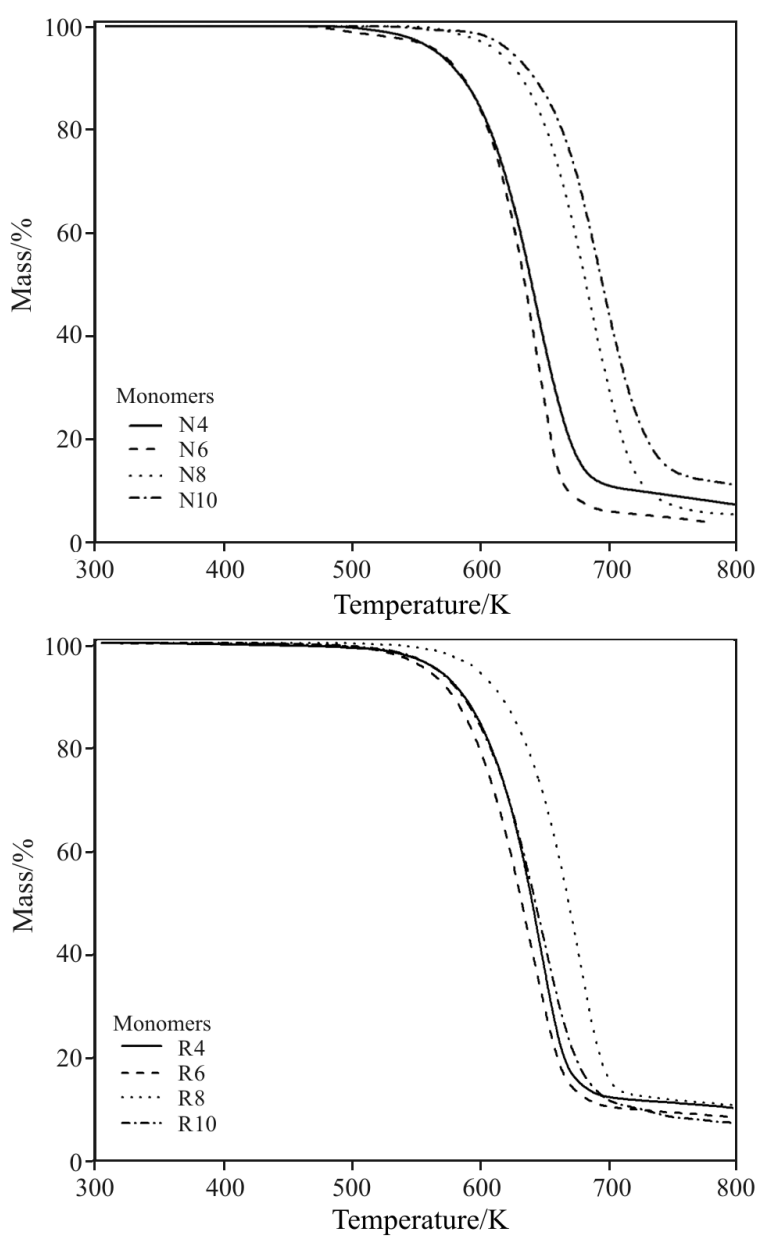

Fig. 2 TG curves of $\mathrm{N}$ and $\mathrm{R}$ monomers

increase of alkoxy chain length in both $\mathrm{N}$ and $\mathrm{R}$ series. PN10 shows highest stability based on IDT. On comparing IDT of polymers of $\mathrm{N}$ and $\mathrm{R}$ series, PN4 and PN6 show more thermal stability than PR4 
Table 2 Thermal behaviors of $\mathrm{N}$ and $\mathrm{R}$ series monomers

\begin{tabular}{lcccccccc}
\hline \multirow{2}{*}{ Monomer } & IDT/K & $D_{\max } / \mathrm{K}$ & IPDT/K & \multicolumn{5}{c}{ Temperature at mass loss \%/K } \\
\cline { 7 - 10 } & & & & $20 \%$ & $40 \%$ & $60 \%$ & $80 \%$ & $90 \%$ \\
\hline N4 & 511 & 651 & 616 & 610 & 634 & 647 & 668 & 720 \\
N6 & 486 & 643 & 605 & 607 & 631 & 640 & 654 & 669 \\
N8 & 569 & 695 & 657 & 654 & 676 & 689 & 709 & 730 \\
N10 & 557 & 695 & 675 & 665 & 685 & 706 & 730 & 848 \\
R4 & 463 & 649 & 617 & 610 & 633 & 649 & 664 & 697 \\
R6 & 490 & 638 & 613 & 600 & 624 & 642 & 659 & 681 \\
R8 & 544 & 681 & 647 & 638 & 661 & 678 & 693 & 725 \\
R10 & 501 & 655 & 612 & 609 & 634 & 653 & 673 & 697 \\
\hline
\end{tabular}
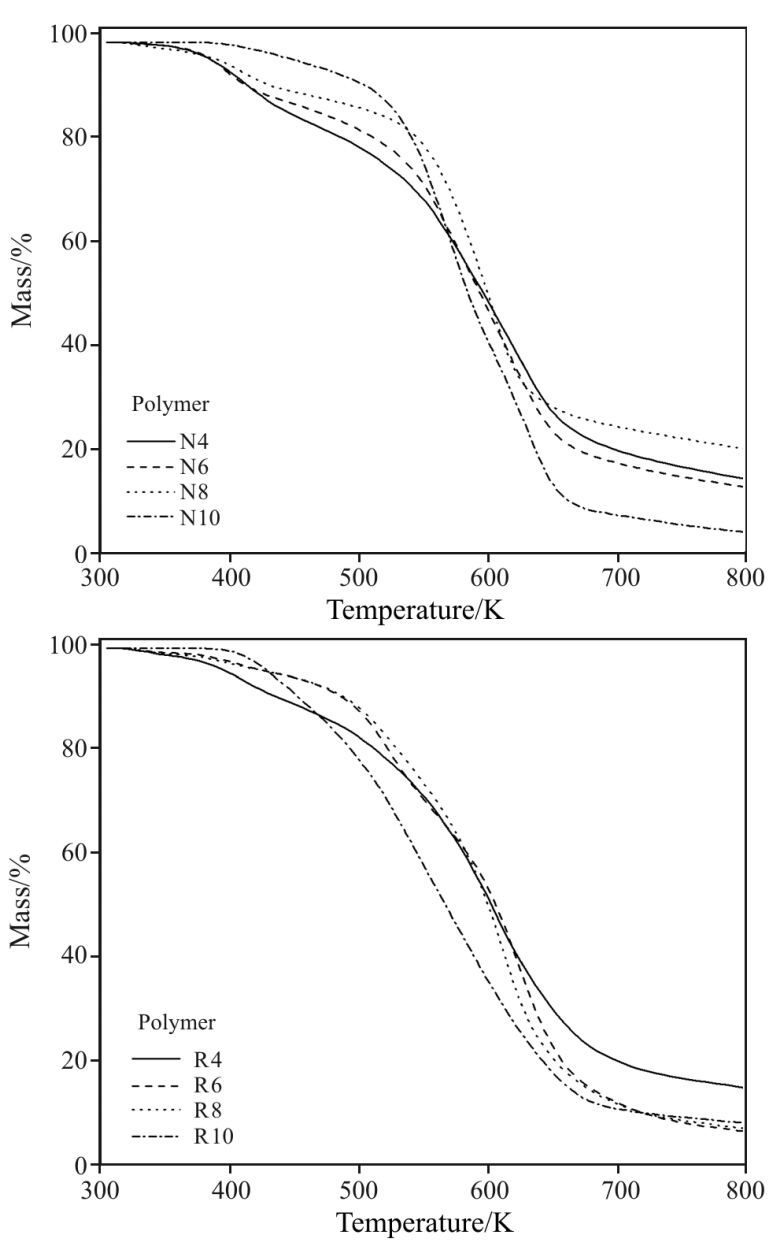

Fig. 3 TG curves of R and N polymers

and PR6. In the case of calculated maximum decomposition temperature $\left(D_{\max }\right)$, the value decrease with the increase of alkoxy chain length.

Integral procedural decomposition temperature (IPDT) as proposed by Doyle provides a semi-quantitative means for comparison of relative thermal stabilities $[16,17]$. The integral procedural decomposition temperature is derived as a means of summing up the whole shape of the normalized data curve. IPDT ac- counts the whole shape of the curve and it sum up all of its dips and meanderings in a single number by measuring the area under the curve. Thus thermal stability of these monomers and polymers has also been determined by calculating IPDT values. To place all materials on an equal procedural footing, the curve is integrated on the basis of the total experimentally accessible temperature ranges. The area under the curve divided by the total area is the total curve area, $A^{*}$, is normalized with respect to both residual mass and temperature. $A^{*}$ is converted to a temperature, $T_{\mathrm{A}^{*}}$, by

$$
T_{\mathrm{A}^{*}}=\left(T_{\text {end }}-T_{\text {ini }}\right) A^{*+}+T_{\text {ini }}
$$

$T_{\mathrm{A}^{*}}$ represents a characteristic end of volatilization temperature rather than an IPDT having practical significance. The second curve area $K^{*}$ can be derived by drawing rectangle bearing $X$-axis upto $T_{\mathrm{A}^{*}}$ and the $Y$-axis mass fraction remaining at $T_{\text {end. }} . K^{*}$ is the ratio between the area under the curve (inside the rectangle) and total rectangle area. The IPDT determined by substituting $A^{*} K^{*}$ for $A^{*}$ in Eq. (1). This index, the integral procedural decomposition temperature is a reproducible datum having practical significance as an integrated half-volatilization temperature. The calculated IPDT value for the monomers and polymers are respectively presented in Tables 2 and 3. In general, in N series monomers, as the chain length increases the IPDT also increases and hence the thermal stability also increases. Overall the IPDT of N10 and R8 are higher than all others of its respective homologs. The presence of<smiles>COC(C)=O</smiles>

link (present in N-series) stabilizes the molecule than<smiles>COC(C)=O</smiles>

link present in R series.

In the case of polymers of $\mathrm{N}$ series, PN10 shows high value of IPDT and the value increases from PN4 
POLYTHIOPHENE CONTAINING MESOGENIC SIDE CHAINS

Table 3 Thermal behavior of $\mathrm{N}$ and $\mathrm{R}$ series polymers

\begin{tabular}{lcccccccc}
\hline \multirow{2}{*}{ Polymer } & IDT/K & $D_{\max } / \mathrm{K}$ & IPDT/K & \multicolumn{5}{c}{ Temperature at mass loss $\% / \mathrm{K}$} \\
\cline { 7 - 10 } & & & & $10 \%$ & $20 \%$ & $30 \%$ & $40 \%$ & $50 \%$ \\
\hline N4 & 383 & 688 & 615 & 490 & 600 & 648 & 689 & 746 \\
N6 & 385 & 679 & 619 & 524 & 609 & 646 & 681 & 724 \\
N8 & 344 & 667 & 625 & 573 & 628 & 655 & 680 & 820 \\
N10 & 430 & 622 & 638 & 583 & 613 & 637 & 667 & 698 \\
R4 & 346 & 667 & 624 & 526 & 608 & 654 & 692 & 750 \\
R6 & 368 & 686 & 639 & 554 & 606 & 656 & 689 & 718 \\
R8 & 356 & 673 & 637 & 559 & 616 & 654 & 678 & 709 \\
R10 & 438 & 590 & 607 & 514 & 570 & 611 & 651 & 697 \\
\hline
\end{tabular}

Table 4 Effect of structure on the level of degradation at different temperatures

\begin{tabular}{lcc}
\hline Monomer & Temperature/K & Mass loss $/ \%$ \\
\hline \multirow{2}{*}{ N4 } & $616-687$ & 61.8 \\
& $687-834$ & 6.8 \\
N6 & $834-949$ & 5.8 \\
& $623-676$ & 56.3 \\
N8 & $676-778$ & 4.6 \\
& $667-735$ & 59.1 \\
& $735-930$ & 6.5 \\
N10 & $930-980$ & 1.7 \\
& $667-747$ & 64.9 \\
R4 & $747-900$ & 6.3 \\
& $900-980$ & 5.4 \\
& $630-677$ & 51 \\
R6 & $677-912$ & 10.1 \\
& $912-982$ & 3.3 \\
& $610-694$ & 66 \\
R8 & $694-883$ & 4.7 \\
& $883-982$ & 3.8 \\
R10 & $651-708$ & 60.3 \\
& $708-912$ & 6.3 \\
\hline
\end{tabular}

to PN8 with the increase of alkoxy chain length. In R series, PR6 showing high value and the addition of alkyl chain length decrease the stability. Comparison of the values obtained for $\mathrm{N}$ and $\mathrm{R}$ series polymers reveal that $\mathrm{R}$ series is showing better stability in terms of IPDT except in PR10 and PN10 is stable than PR10.

The extracted degradation data of monomers and polymers obtained from curves are presented in Tables 2 and 3, respectively. In monomers of $\mathrm{N}$ series, the temperature at which $20,40,60,80$ and $90 \%$ mass loss occurs increase, with the increase of alkoxy chain length. For N4 monomer, 20\% of mass loss is observed at $610 \mathrm{~K}$ while it occurs at $665 \mathrm{~K}$ in N10 monomer.
Table 5 Effect of structure on the level of degradation at different temperatures

\begin{tabular}{|c|c|c|}
\hline Polymer & Temperature/K & Mass loss $/ \%$ \\
\hline N4 & $\begin{array}{l}400-462 \\
462-596 \\
596-673 \\
673-736 \\
736-917\end{array}$ & $\begin{array}{r}6.0 \\
11.4 \\
16.7 \\
13.0 \\
7.1\end{array}$ \\
\hline N6 & $\begin{array}{l}394-435 \\
435-585 \\
585-658 \\
658-730 \\
730-918\end{array}$ & $\begin{array}{r}3.9 \\
10.0 \\
17.7 \\
17.7 \\
6.3\end{array}$ \\
\hline N8 & $\begin{array}{l}406-450 \\
450-597 \\
597-654 \\
654-698 \\
698-917\end{array}$ & $\begin{array}{r}2.9 \\
7.4 \\
17.2 \\
14.9 \\
7.8\end{array}$ \\
\hline N10 & $\begin{array}{l}431-585 \\
585-680 \\
680-735 \\
735-917\end{array}$ & $\begin{array}{r}10.4 \\
32.6 \\
14.8 \\
4.3\end{array}$ \\
\hline $\mathrm{R} 4$ & $\begin{array}{l}402-535 \\
535-629 \\
629-763 \\
763-917\end{array}$ & $\begin{array}{r}8.8 \\
13.0 \\
27.5 \\
5.1\end{array}$ \\
\hline R6 & $\begin{array}{l}406-532 \\
532-660 \\
660-730 \\
730-812 \\
812-917\end{array}$ & $\begin{array}{r}5.8 \\
23.4 \\
22.2 \\
6.7 \\
2.4\end{array}$ \\
\hline $\mathrm{R} 8$ & $\begin{array}{l}394-539 \\
539-641 \\
641-711 \\
711-787 \\
787-918\end{array}$ & $\begin{array}{r}6.1 \\
18.9 \\
24.2 \\
7.8 \\
3.2\end{array}$ \\
\hline R10 & $\begin{array}{l}437-549 \\
549-629 \\
629-749 \\
749-918\end{array}$ & $\begin{array}{r}14.5 \\
18.7 \\
22.8 \\
3.4\end{array}$ \\
\hline
\end{tabular}

The results show that in general, the temperature at which the $10 \%$ mass was lost increase with the increase of chain length of $\mathrm{N}$ and $\mathrm{R}$ polymers. The tem- 
perature at which 20,30 and $40 \%$ mass loss was obtained also increases as the chain length increases from N4 to N8. Unlike monomer series, N10 polymer shows degradation at lower temp itself. In the case of $\mathrm{R}$ series polymers, no characteristic relation could be understood between the alkoxy chain length and degradation. Similar to that of PN10, PR10 polymer also shows poor thermal stability on the basis of mass loss.

Effect of structure on the level of degradation at different temperatures is given in the Tables 4 and 5 for the monomers and polymers, respectively. All monomers undergo 3-stage degradation except N6 monomer where only two-stage degradation is observed. The polymer PN10 and PR10 undergoes four-stage degradation while other polymers of $\mathrm{R}$ and $\mathrm{N}$ series undergo 5-stage degradation.

Overall, the obtained results from thermal studies suggest that in monomers, the melting and the isotropic temperatures decrease linearly with the increase of aliphatic segment and the characteristic texture of all monomers are same viz, nematic phase. In polymers, irrespective of the linkage, the $1^{\text {st }}$ transition temperature is same. The thermal stability of N10 and R8 monomers are found is high on the basis of IDT and IPDT. In the case of polymers, the overall thermal stability of the PN10 is high since it exhibits high value of initial decomposition temperature as well as integral procedural decomposition temperature.

\section{References}

1 L. Akcelrud, Prog. Polym. Sci., 28 (2003) 875.

2 A. Kraft, A. C. Grimsdale and A. B. Holmes, Angew. Chem. Int. Ed., 37 (1998) 402.

3 J. Roncali, Chem. Rev., 97 (1997) 173.

4 K. Akagi, M. Narita, R. Toyoshima and H. Shirakawa, Mol. Cryst. Liq. Cryst., 318 (1998) 157.

5 H. S. Nalwa (Ed.), Handbook of Organic Conductive Molecules and Polymers: Vol. 3, Conductive Polymers: Spectroscopy and Physical Properties. John Wiley and Sons Ltd., 1997.

6 N. Somanathan and G. Wegner, Synth. Met., 75 (1995) 123.

7 S. Radhakrishnan, V. Subramanian and N. Somanathan, Org. Electron., 5 (2004) 227.

8 A. M. L. Silva, R. W. C. Li, J. R. Matos and J. Gruber, J. Therm. Anal. Cal., 59 (2000) 675.

9 K. Pielichowski, J. Thermal Anal., 54 (1998) 171.

10 F. D. Bellamy and K. Ou, Tett. Lett., 25 (1984) 839.

11 A. Bolognesi, C. Botta, C. Mercogliano, M. Marnelli, W. Porzio, L. Angiolini and E. Salatelli, Polym. Adv. Technol., 14 (2003) 537.

12 H. Westfahl Jr., J. Therm. Anal. Cal., 79 (2005) 579.

13 R. Lopez-Fonseca, I. Landa, M. A. Gutierrez-Ortiz and J. R. Gonzalez-Velasco, J. Therm. Anal. Cal., 80 (2005) 65.

14 K. Pielichowski and B. Janowski, J. Therm. Anal. Cal., 80 (2005) 147.

15 J. M. Salla, J. M. Morancho, X. Ramis and A. Cadenato, J. Therm. Anal. Cal., 80 (2005) 163.

16 C. D. Doyle, Anal. Chem., 33 (1961) 77.

17 G. Sumana and D. C. Gupta, J. Polym. Mater., 21 (2004) 259.

Received: May 19, 2005

Accepted: August 19, 2005

OnlineFirst: January 11, 2006

DOI: $10.1007 / \mathrm{s} 10973-005-7110-0$ 